NBER WORKING PAPER SERIES

THE ROLES OF MONEY AND CRFDIT

IN MACROECONOMIC ANALYSIS

\author{
Benjamin M. Friedman
}

Working Paper No. 831

\author{
NATIONAI, BUREAU OF ECONOMIC RESEARCH \\ 1050 Massachusetts Avenue \\ Cambridge MA 02138 \\ December 1981
}

The research reported here is part of the NBER's research program in Financial Markets and Monetary Economics. Any opinions expressed are those of the author and not those of the National Bureau of Economic Research. 


\title{
Abstract
}

This paper considers the implications, for macroeconomic modelling and for monetary policy, of the interrelationships among money, credit and nonfinancial economic activity. Data for the United States since World War II show that the volume of outstanding credit is as closely related to economic activity as is the stock of money, and moreover that neither money nor credit is sufficient to account fully for the effect of financial markets in determining real economic activity. Instead, what appears to matter is an interaction between money and credit. This result is consistent with a macroeconomic modelling strategy that deals explicitly with both the money market and the credit market, and with a monetary policy framework based on the joint use of a money growth target and a credit growth target.

\author{
Benjamin M. Friedman \\ Harvard University \\ Department of Economics \\ Littauer Center 127 \\ Cambridge, Massachusetts 02138 \\ (617) 495-4246
}




\section{THE ROLES OF MONEY AND CREDIT IN MACROECONOMIC ANALYSIS}

\section{Benjamin M. Friedman* \\ Harvard University}

In thinking about the relationships between nonfinancial economic activity and quantity measures of what is happening in the financial markets, most economists and most economic policy makers today focus primarily - if not exclusively - on money. At the theoretical level, the implicit assumption underlying most current macroeconomic analysis is that the money stock is both necessary and sufficient to represent the relevant information contained in financial quantities. Almost every macroeconomic model, no matter how simplified, includes the money stock among the variables it represents explicitly, and few such models include any financial quantities other than money. At the applied policy level, the formulation of monetary policy in most of the industrialized western countries takes place in terms of target rates of monetary growth. The most prominent exception to the pervasive emphasis on money in macroeconomic analysis is that the large macroeconometric models often do include non-money financial quantities, but even here such variables are usually only peripheral. ${ }^{1}$

This single-minded devotion to the money stock raises issues that go beyond mere questions of definition. Any specific monetary aggregate is, after all, a collection of certain of the public's financial assets. Although it would strain the meaning of the word "money" to include in it such items as equity claims and long-term debt instruments, as long as the focus of analysis is exclusively on the public's assets the question of which ones to include is, in the end, a matter of definition. ${ }^{2}$ The more fundamental issue stems from the underlying reality that any balance sheet has two sides. 
Except in the trivial sense that the entirety of the public's assets equals the entirety of its liabilities plus net worth, the distinction between assets and liabilities - between money and credit - is not definitional. Merely redefining ways of adding up the various items on the asset side of the public's balance sheet is not sufficient if there is also valuable information contained in the liability side.

What accounts for the current preoccupation with money to the exclusion of other financial quantities? Is there something about money that is "special" in an a priori sense, or is the reason instead an empirical presumption that, for reasons unexplained, variations in money somehow correspond more closely to the variations in the nonfinancial aggregates which are the primary object of macroeconomic inquiry?

Apart from government-issued base money, which is usually not the definition that people have in mind either in economic analysis or in discussions of monetary policy, ${ }^{3}$ there is nothing "special" about money in an a priori sense. In the simplest abstraction of an economy with no privately issued financial instruments, base money is the only financial asset, and there are no liabilities. In modern economies, however, most money is not base money but bank money, and privately issued financial instruments constitute the great majority of all such instruments issued, held and traded. For given growth in base money (if that is what the relevant authority does in fact control), the behavior of the banking system and that of the nonbank public together determine the growth of both bank money and bank credit, and do so jointly with the determination of nonbank financial assets and liabilities as well as nonfinancial economic activity. Economic theory provides no a priori reason at all to expect a role for the nonbank public's money holdings but not its credit liabilities.

The reason for emphasizing money in macroeconomic analysis must 
instead be a set of presumptions about the empirical relationships connecting money and the behavior of key measures of nonfinancial economic activity, including especially income and prices. Indeed, during the last two decades a vast literature has developed documenting money-income and money-price relationships, in a variety of forms corresponding to variations in the underlying theoretical framework, and for a large number of different countries and different time periods.

Now more recent work has shown that, at least for the United states during the period since the 1951 Treasury-Federal Reserve Accord, the relationship between economic activity and the public's outstanding credit liabilities exhibits the same degree of regularity and stability as does the relationship between economic activity and the public's holdings of money balances. Moreover, still incomplete analysis suggests that the approximately equal regularity of the credit-income and money-income relationships holds for other countries as well, including Canada, Germany, Japan and the United Kingdom. 4

The object of this paper is to present the empirical case for a redirection of emphasis in macroeconomic research, as well as in the formulation of monetary policy, away from the sole focus on money among financial quantities. The goal is not to show that the money stock contains no information that is useful in these two contexts, nor even to suggest that some non-money quantity dominates the money stock in these contexts and therefore should replace it as the fulcrum of analysis. The point is simply that the available empirical evidence does not warrant an exclusive focus on any one financial quantity. Moreover, if for some reason there is a need to focus on just one financial quantity, the evidence provides no reason to conclude that that one should be a monetary aggregate rather than a 
credit aggregate.

Section I reviews the evidence documenting the approximately equal regularity and stability of the relationships between money and income and between credit and income in the United States. Merely finding empirical regularities settles few interesting questions, however. Indeed, it is difficult to think of a familiar economic hypothesis that is contradicted merely by the finding of a close relationship between credit and income. It could always be the case, of course, that the operative chain of causation ran from money to income and thence from income to credit, so that the public's decisions with respect to credit liabilities remained a peripheral aspect of economic behavior, one which macroeconomic analysis could safely ignore in the interest of simplification.

Section II examines evidence bearing on the interaction among money, credit and economic activity, drawn from statistical investigations that are prior to structural economic model building. ${ }^{5}$ Here too the results provide no justification for a special emphasis on money to the exclusion of credit in macroeconomic analysis. At the same time, the results do go beyond merely indicating parallel roles for money and credit. Especially in the context of the determination of real income, what apparently matters is neither money nor credit alone but rather the interrelationship between them. Section III goes on to consider what kind of structural economic model would be consistent with this set of empirical observations. This line of investigation inevitably leads to the issue of the role of financial prices (in other words, interest rates), in addition to financial quantities, in determining nonfinancial economic behavior. Here the evidence indicates a significant, but still less than complete, connection between the relationship of income to credit documented in Sections I-II and the familiar 
relationship of income to interest rates documented in a precise way in other recent work. Because the interest rate is the price of credit in terms of money, this analysis leads naturally to the idea of a three-market model - including the markets for goods and services, for money and for credit - as an appropriate framework for structural analysis. Section IV brings together the major conclusions reached in the paper and then explores their implications for monetary policy. In the absence of evidence supporting a special role for money in macroeconomic behavior, there is little support for the intermediate target procedure as currently implemented with monetary aggregates as the sole intermediate targets. One alternative, of course, would be to abandon intermediate targets altogether and focus directly on the ultimate nonfinancial objectives of monetary policy. Alternatively, a two-target framework combining one monetary aggregate and one credit aggregate offers some advantages over the current emphasis on monetary aggregates alone, in that it would at least facilitate the formal incorporation into the monetary policy structure of information from both sides of the public's balance sheet. 
I. The Relative Stability of the Money-Income and Credit-Income Relationships

Results based on a variety of methodological approaches consistently indicate that the aggregate outstanding indebtedness of all nonfinancial borrowers in the United States bears as close and as stable a relationship to U.S. nonfinancial economic activity as do the more familiar asset aggregates like the money stock (however defined) or the monetary base. 6 Moreover, in contrast to the familiar asset aggregates, among which there appears to be little basis for choice from this perspective, total nonfinancial debt appears to be unique in this regard among major liability aggregates.

Figure 1 plots data for 1946-80 showing the yearend credit market indebtedness, as a percentage of fourth-quarter gross national product, for the aggregate of all U.S. nonfinancial borrowers and for five different categories of borrowers that together comprise the total. ${ }^{7}$ These data are "net" in the sense that they net out financial intermediation. For example, the data include such items as a household's mortgage issued to a bank, or a corporation's bonds sold to an insurance company, but they exclude any liability issued in turn by the bank or the insurance company in order to finance that lending activity. The data also exclude debt issued by separate financial subsidiaries of nonfinancial corporations, as well as by federally sponsored credit agencies and mortgage pools. The data are "gross," however, in the sense that they include all of an individual household or firm's outstanding credit market liabilities, not just any excess of liabilities over either financial or total assets, and also in the sense that they include one household's borrowing from another or one firm's borrowing from another.

The strong stability of the total nonfinancial debt ratio, shown in 


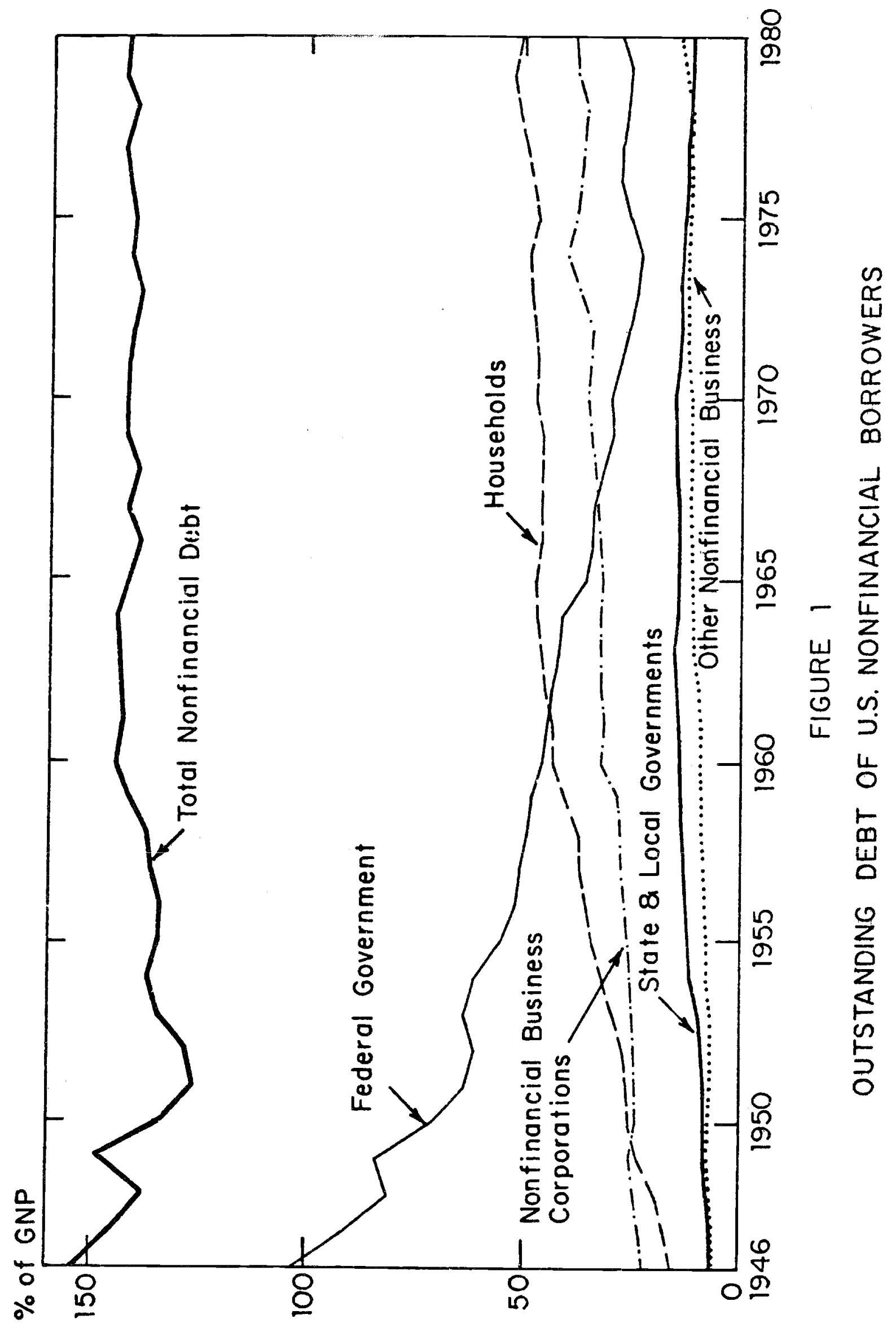


the top line in the figure, stands out in stark contrast to the variation of the individual sector components. The nonfinancial economy's reliance on debt, scaled in relation to economic activity, has shown almost no trend and but little variation since World War II. After falling from 155.6\% of gross national product in 1946 to $126.6 \%$ in 1951 and then rising to 143.98 in 1960 , the total has remained within a few percentage points of that level ever since (the 1980 level was 142.9\%). ${ }^{8}$ Otherwise it has exhibited a slight cyclicality, typically rising a percentage point or two in recession years (when gross national product, in the denominator, is weak).

The individual components of this total, however, have varied in sharply different directions both secularly and cyclically. In brief, the secular postwar rise in private debt has largely mirrored a substantial decline (relative to economic activity) in federal government debt, while bulges in federal debt issuance during recessions have mostly had their counterpart in the abatement of private borrowing. Households have almost continually increased their reliance on debt in relation to their nonfinancial activity throughout this period. Both corporations and unincorporated businesses have also issued steadily more debt, on a relative basis, except for temporary retrenchments during recession years. State and local governments steadily increased their relative debt issuing activity during the 1950 s and 1960s, but just as steadily reduced it during the 1970s. Except only for $1975-76$ and 1980 , the federal government has reduced its debt ratio in every year since 1953, although this relative shrinkage of the federal debt has been slower in years when recession has temporarily inflated the budget deficit (and, again, depressed gross national product in the denominator). The first four columns of Table 1 summarize the stability of the ratios to gross national product of ten financial aggregates - five liability 


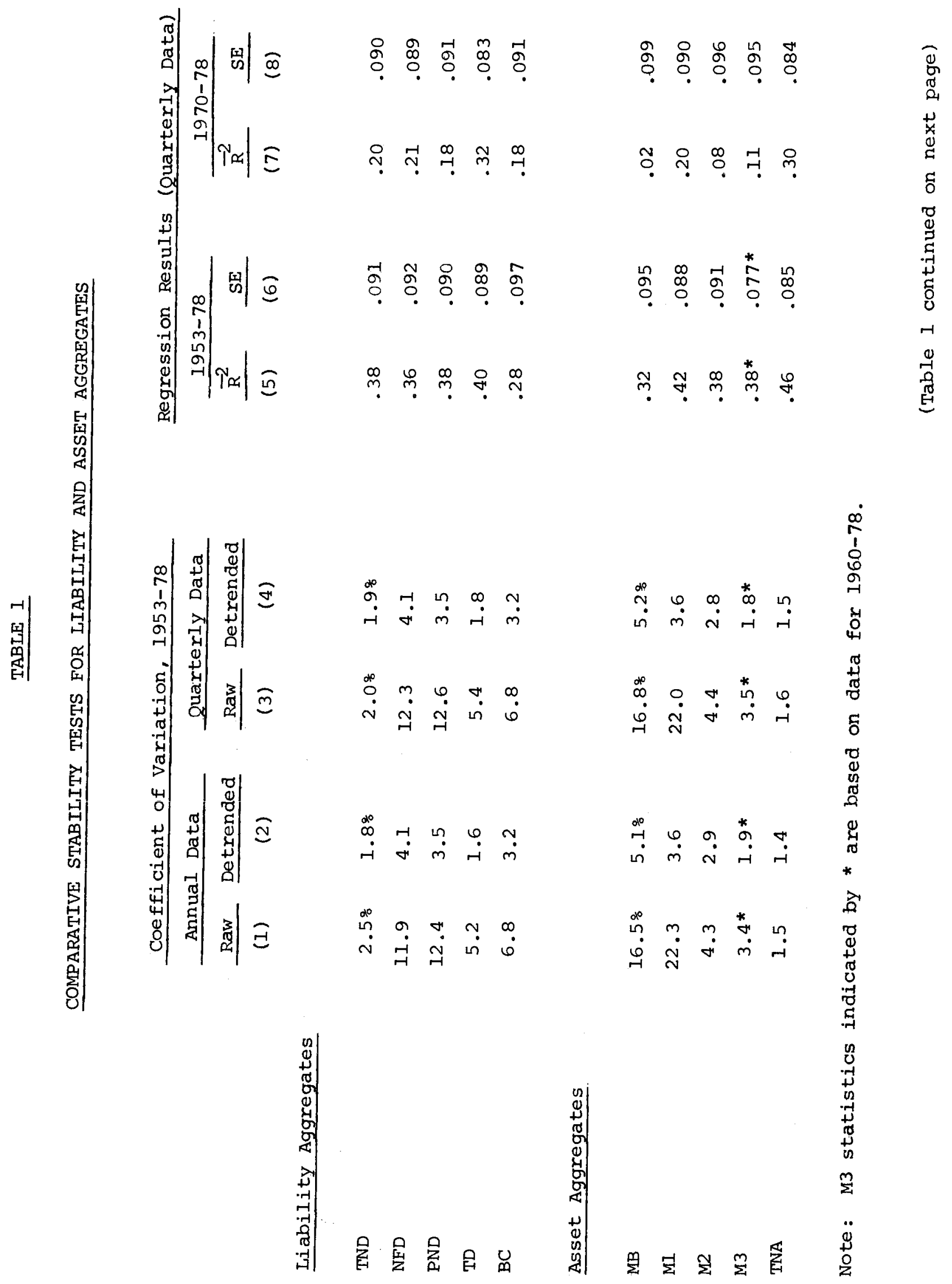



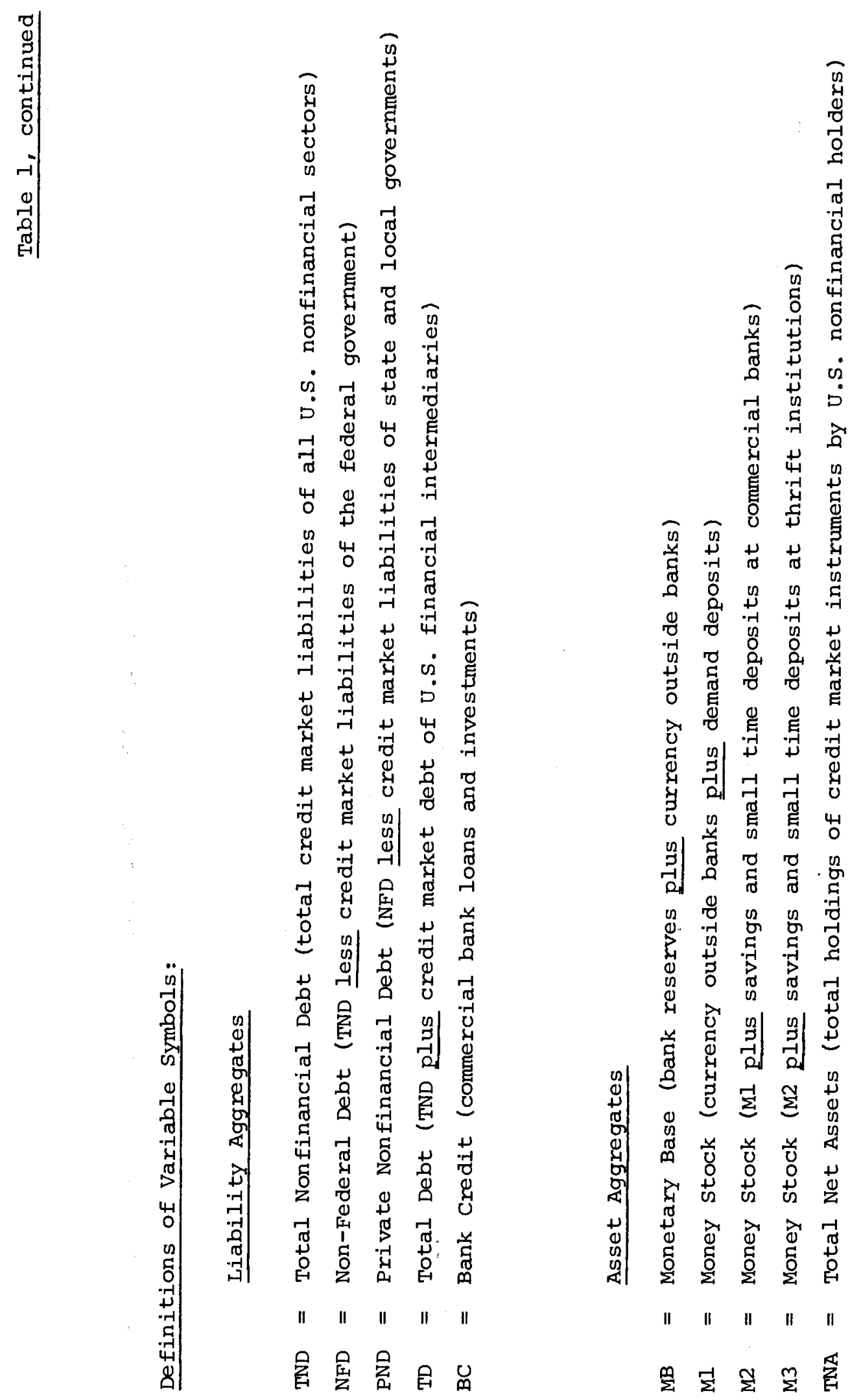
groupings, including the "total nonfinancial debt" measure plotted in Figure 1 , and five asset groupings - by showing the coefficient of variation (standard deviation normalized by mean) for each ratio computed from both annual and quarterly U.S. data over the 1953-78 sample period lexcept for the M3 money stock, for which data begin only in 1959). In each case the table shows the coefficient of variation computed from raw data, and also computed from detrended data.

As columns (1) and (3) of Table 1 show, the comparison for data including time trends indicates that total net assets and total nonfinancial debt are (in that order) the most stable, while the Ml money stock and the monetary base (in that order) are the least stable, among the ten aggregates. Whether or not a particular relationship exhibits a time trend, however, has little to do with its "stability" in the usual economic sense. The corresponding comparison for detrended data, shown in columns (2) and (4), again indicates that total net assets is the most stable aggregate in relation to gross national product, with total debt and total nonfinancial debt, respectively, a close second and third. The monetary base exhibits the least stability on a detrended basis, with private nonfinancial liabilities and the MI money stock close behind. Orderings based on annual data are essentially the same as those based on quarterly data.

Simple ratios of precisely contemporaneous observations may well fail to capture the relevant concept of "stability" in the relationship among variables that move over time with some general lead or lag pattern between them. The remaining columns of Table 1 present the respective coefficients of determination and standard errors of ten estimated regression equations, in each case relating the growth of nominal gross national product to a moving average of the growth of one of the ten financial 
aggregates listed in the table, plus a moving average of a fiscal policy measure. The equations are estimated in the familiar form

$$
\Delta Y_{t}=\alpha+\sum_{i=0}^{4} \beta_{i} \Delta F_{t-i}+\sum_{i=0}^{4} \gamma_{i} \Delta E_{t-i}
$$

where $\mathrm{Y}$ is gross national product, $\mathrm{F}$ is any of the five liability aggregates or five asset aggregates and $\mathrm{E}$ is federal government expenditures calculated on a high employment basis, all expressed in natural logarithms, and $\alpha$, the $\beta_{i}$ and the $\gamma_{i}$ are scalar coefficients, with the $\beta_{i}$ and $\gamma_{i}$ constrained to lie along respective fourth-order polynomials with the implied $\beta_{-1}=\beta_{5}=$ $\gamma_{-1}=\gamma_{5}=0$

Colums (5) and (6) of Table 1 show the results of estimating equations of the form (1) using quarterly data for the same 1953-78 sample period used in comparing the simple ratios. Total net assets performs best in this test, with a standard error of $0.85 \%$ per quarter in "explaining" the historical growth of gross national product, while bank credit (standard error 0.97\%) performs worst. Total nonfinancial debt is about in the middle. Because there is evidence of a significant break in most of these regressions at around 1970, however - probably associated with the Federal Reserve system's change to a monetary target strategy and/or the elimination of the Regulation $Q$ interest ceiling from large certificates of deposit, both of which occurred in 1970 - columns (7) and (8) also show the respective results for analogous regression equations based on data for 1970-78 only. ${ }^{9}$ For this shorter period the relative performance of total nonfinancial debt is somewhat better, equalling that of the Ml money stock.

In part because of the extent to which regressions of the form (I) have been discredited by a variety of criticisms, researchers examining the money-income (or, here, credit-income) relationship have increasingly 
turned to methods that allow for a richer dynamic interaction between money and income by relating the variation of income not to the entirety of the variation of money but only to that part of it which cannot already be de'duced either from the past history of money itself or from the joint past history of both money and income. ${ }^{10}$ In this context a key indication of the stability of the relationship to income of any financial aggregate is the behavior of that relationship following just such an "innovation," or unanticipated movement, in the aggregate (or in income). A more general representation of ( 1 ) that is consistent with this interpretation (but that omits the fiscal variable, so as to keep the order of the system small) is the vector autoregression

$$
\left|\begin{array}{l}
Y_{t} \\
F_{t}
\end{array}\right|=\left|\begin{array}{l}
\alpha_{1} \\
\alpha_{2}
\end{array}\right|+\left|\begin{array}{ll}
B_{11} & B_{12} \\
B_{21} & B_{22}
\end{array}\right|\left|\begin{array}{l}
Y_{t-1} \\
F_{t-1}
\end{array}\right|+\left|\begin{array}{l}
\mu_{1 t} \\
\mu_{2 t}
\end{array}\right|
$$

where $Y$ and $F$ are again as in (1), the $\mu_{i}$ are disturbances, the $\alpha_{i}$ are Fixed scalar coefficients to be estimated, and the $B_{i j}$ are fixed-coefficient lag operator polynomials to be estimated.

Solution of the autoregression (2), once it is estimated, yields a moving-average representation of the form

$$
\left|\begin{array}{l}
Y_{t} \\
F_{t}
\end{array}\right|=\left|\begin{array}{l}
\xi_{1} \\
\xi_{2}
\end{array}\right|+\left|\begin{array}{ll}
\theta_{11} & \theta_{12} \\
\theta_{21} & \theta_{22}
\end{array}\right|\left|\begin{array}{l}
\mu_{1 t} \\
\mu_{2 t}
\end{array}\right|
$$

where the $\xi_{i}$ and $\Theta_{i j}$ are respectively fixed scalar coefficients and fixedcoefficient lag operator polynomials derived from recursive substitution of the $\alpha_{i}$ and $B_{i j}$ from (2) to express both $Y$ and $F$ as functions of the current values and past histories of both $\mu_{1}$ and $\mu_{2}$, and the normalization convention imposed in estimating (2) constrains the zero-lag elements of the four polynomials in (3) to $\theta_{11}=\theta_{22}=1$ and $\theta_{12}=\theta_{21}=0$ (so that $\mu_{1}$ is "the $Y$ disturbance" and $\mu_{2}$ "the $F$ disturbance"). The orthogonalization of (3) that extracts the independent part of $\mu_{2}\left(\right.$ say, $\left.\varepsilon_{2}\right)$ as "the $F$ innovation" 
is then just

$$
\left|\begin{array}{l}
Y_{t} \\
F_{t}
\end{array}\right|=\left|\begin{array}{l}
\xi_{1} \\
\xi_{2}
\end{array}\right|+\left|\begin{array}{ll}
\phi_{11} & \phi_{12} \\
\phi_{21} & \phi_{22}
\end{array}\right|\left|\begin{array}{l}
\varepsilon_{1 t} \\
\varepsilon_{2 t}
\end{array}\right|
$$

where the $\phi_{i j}$ and the $\varepsilon_{i}$ follow from the $\theta_{i j}$ and the $\mu_{i}$, respectively, and the $\varepsilon_{i}$ are now independent. ${ }^{11}$

The upper half of Table 2 summarizes simulations of (4), estimated

in the form (1) using quarterly data for nominal gross national product and three each of the liability and asset aggregates from Table 1, with eight quarters of lags on each variable in each equation. For convenience the table reports the response of $F / Y$ rather than the individual responses of $F$ and $Y$ separately. Each column in the table presents values, for the initial quarter and then for the final quarter in each of the first five years, indicating the time path followed by $F / Y$ (for the definition of $F$ indicated) in response to a $1 \%$ innovation in $\mathrm{F}$.

What stands out in these results is the contrast between the time paths for the three asset aggregate ratios, each of which declines rapidly albeit irregularly after such an innovation, and those for the three liability aggregate ratios. The total nonfinancial debt ratio declines rapidly too, indicating about the same stability in this respect as does any of the asset aggregates; but both the (narrower) private nonfinancial debt ratio and the (broader) total debt ratio show pronounced instability, with overshooting lasting up to three years beyond the initial innovation in F. ${ }^{12}$

A further aspect of the tendency in recent research to avoid simple nominal income regressions of the form (1) has been a reluctance to ignore the distinction between the real and price components of nominal income variation. The lower half of Table 2 summarizes simulations that are analogous to those shown in the upper half of the table but based on the moving- 


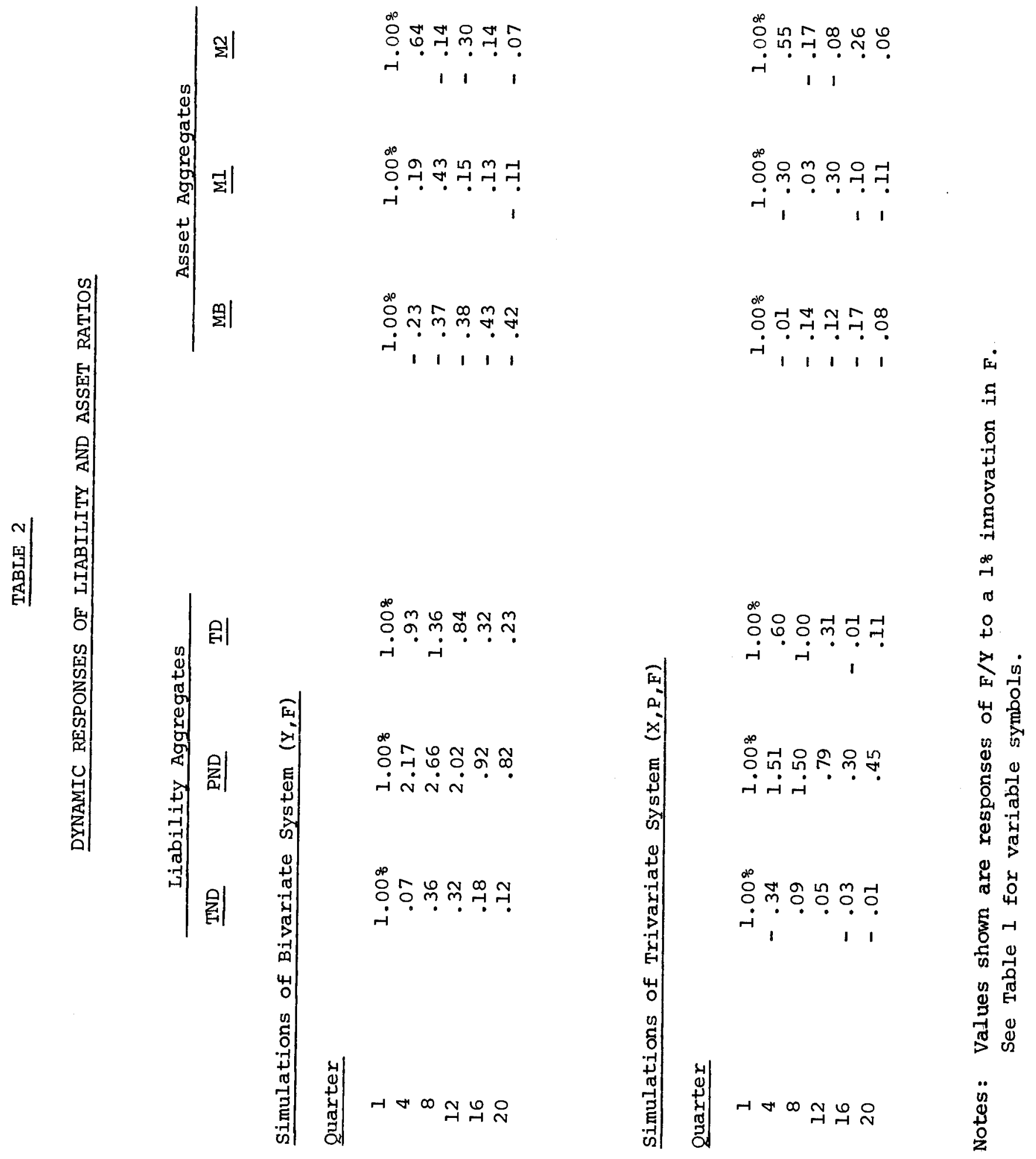


average representation solved out from the trivariate vector autoregression

$$
\left|\begin{array}{l}
X_{t} \\
P_{t} \\
F_{t}
\end{array}\right|=\left|\begin{array}{l}
\alpha_{1} \\
\alpha_{2} \\
\alpha_{3}
\end{array}\right|+\left|\begin{array}{lll}
B_{11} & B_{12} & B_{13} \\
B_{21} & B_{22} & B_{23} \\
B_{31} & B_{32} & B_{33}
\end{array}\right|\left|\begin{array}{l}
X_{t-1} \\
P_{t-1} \\
F_{t-1}
\end{array}\right|+\left|\begin{array}{l}
\mu_{1} \\
\mu_{2} \\
\mu_{3}
\end{array}\right|
$$

where $\mathrm{X}$ is real gross national product and $\mathrm{P}$ is the price deflator (both in natural logarịthms). Once again the results show a fairly rapid return of the $F /(X \cdot P)$ ratio after an innovation in any of the three asset aggregates and also in total nonfinancial debt, but a slower and less stable return after an innovation in either private nonfinancial debt or total debt.

Among the various liability measures considered, therefore, these results suggest that there is indeed something unique about total nonfinancial debt. It is as if the $M 1$ money stock ratio were sharply unstable, but adding commercial bank time and saving deposits to form the M2 money stock ratio yielded stability, and further adding thrift institution deposits to form the M3 money stock ratio destroyed that stability - none of which appears to happen. Hence not only does the total nonfinancial debt ratio exhibit just as much stability as any of the five asset ratios in these dynamic tests, it does so uniquely among the various liability aggregates tested.

In sum, the evidence provided by a variety of methodologies shows that at least one aggregate measure of outstanding credit liabilities in the United states - total nonfinancial debt - consistently exhibits just as much stability in relation to U.S. economic activity as do the more familiar asset aggregates. Indeed, the debt-to-income relationship measured in this way can appear to be more stable than any particular money-to-income relationship, depending on the specific measure of money and the specific test used. 
Regardless of whether the credit-income relationship is "as stable as" or "more stable than" that for money, however, like the money-income relationship it is potentially important for understanding economic behavior. Nevertheless, although the money-income relationship has long been the focus of attention, the credit-income relationship has to date stimulated little investigation. 
II. Money, Credit, Income and Prices

The mere finding of a regular empirical relationship between the outstanding debt of nonfinancial borrowers and the economy's nonfinancial activity is suggestive, but it is not necessarily of direct importance for either economic model building or economic policy making. For example, what if the explanation for this observed phenomenon were simply that people always adjusted their borrowing to stay in line with their incomes, while their real spending and saving decisions remained predetermined with respect to their activity in the credit market? The total nonfinancial debt variable in that case would be interesting from the standpoint of an investigation of the credit market per se, but there would be little sacrifice to economic analysis in omitting it from a model primarily intended to deliver insights into the determination of nonfinancial behavior itself.

Alternatively, what if the observed stability of the credit-to-income relationship reflected the outcome of a process in which people took decisions with respect to their spending and borrowing behavior jointly? such a process could emerge if spending and saving decisions were sensitive to the expected yield levels that cleared the credit market, for example, or if the credit market did not clear and people's ability to spend were constrained by their ability to borrow. In that case a model that failed to account for whatever joint decision process connected spending behavior and borrowing behavior would be inadequate, even if understanding the determination of nonfinancial activity constituted the sole objective of the analysis.

The same arguments apply, of course, to the role in economic analysis of money (or other asset aggregates). Nevertheless, although few models of macroeconomic behavior include an explicit representation of the credit market, almost all include at least a money demand function and an equilibrium condition 
for the money market, and many go on to treat the supply of money in some detail as well. Were it not for evidence like that summarized in section I, it would perhaps be possible to rationalize this disparity on empirical grounds - although, even so, the distinction between making money an integral or a peripheral part of the analysis would again depend on whether or not the money market played a role in determining nonfinancial economic activity.

In light of the evidence summarized above showing that there is little to distinguish the respective stability of the money-income and credit-income relationships on empirical grounds, however, the rationalization for including the money market but excluding the credit market in macroeconomic analysis must hinge on a presumption that money is central to nonfinancial decisions while credit is not - in other words, that people jointly determine how much to spend and save and how much money to hold, but only secondarily determine how much to borrow.

Is there evidence to support this distinction? Just what constitutes evidence in this context depends in large part on what it means for two actions to be jointly determined or, alternatively, for one to be predetert mined with respect to another. "Causality" is a concept with a precise meaning in logic (indeed, several precise meanings), but there is little prospect of using time-series evidence to settle directly questions of economic causality. 13 "Exogeneity" is a concept with a precise meaning in econometrics, and time-series evidence is better suited to bear on questions of econometric exogeneity. In recent years the literature of this subject has therefore moved away from asserting that one variable "causes" another to the alternative formulation that the one "is exogenous with respect to" the other. Even so, as the development of this literature during the past 
decade has amply shown, whether one variable is or is not predetermined with respect to another, even in the narrower sense of econometric exogeneity, depends on (among other considerations) what if any third or further variables the analysis incorporates. 14

Perhaps the best way of formulating the question at hand so as to convey the actual meaning of the tests developed for such purposes by Granger [9] and Sims [18] is to ask whether one variable "incrementally predicts" or "incrementally explains" another. Because the basis of such tests consists of regression equations relating one variable to lagged values of another, the issue is really whether the lagged variation of the right-hand-side variable predicts (in beyond-sample analysis) or explains (in within-sample analysis) the variation of the left-hand-side variable. The relevant prediction or explanation is not absolute but incremental, however, in that the lagged values of the specific right-hand-side variable which is the focus of the inquiry are not the equation's only regressors. Hence the question these tests address is, more accurately, whether the lagged values of that specific right-hand-side variable make an incremental contribution to the equation's predictive or explanatory capacity over and above that already provided at least by lagged values of the left-hand-side variable itself and perhaps by lagged values of still other variables as well.

Put in these terms, one rationale for focusing on the money market but not the credit market in macroconomic analysis would be a presumption that money incrementally explains real economic behavior in a way that credit does not. Table 3 summarizes evidence testing this proposition, drawn from two of the trivariate vector autoregression systems estimated as in (5) above. The upper half of the table presents statistics for the estimation 
$\underset{I_{1}}{\overparen{U}}$

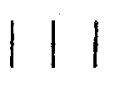

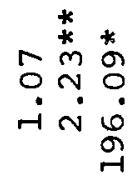

$\sum_{[1} \mid$

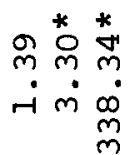
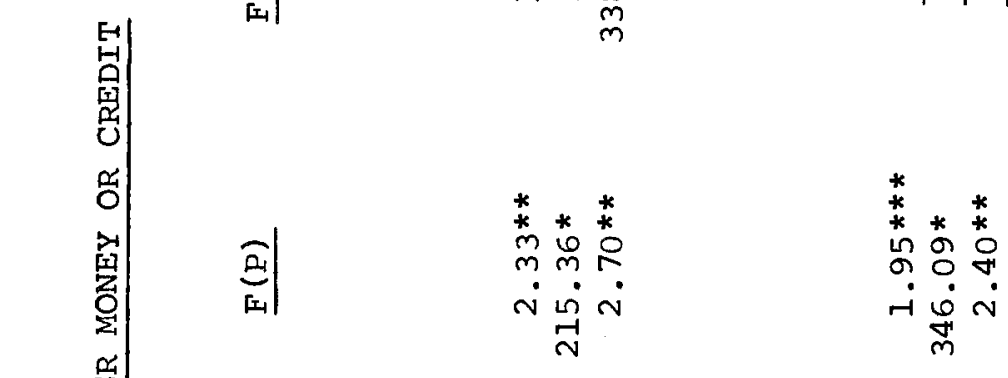

$\frac{x}{\mid x}$
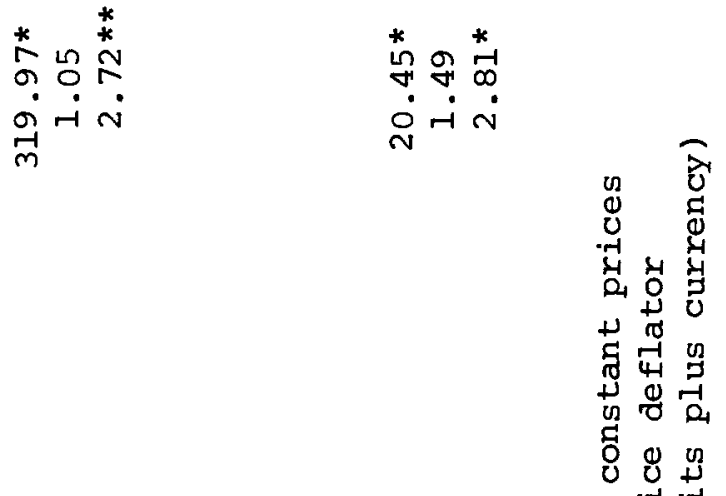

勿

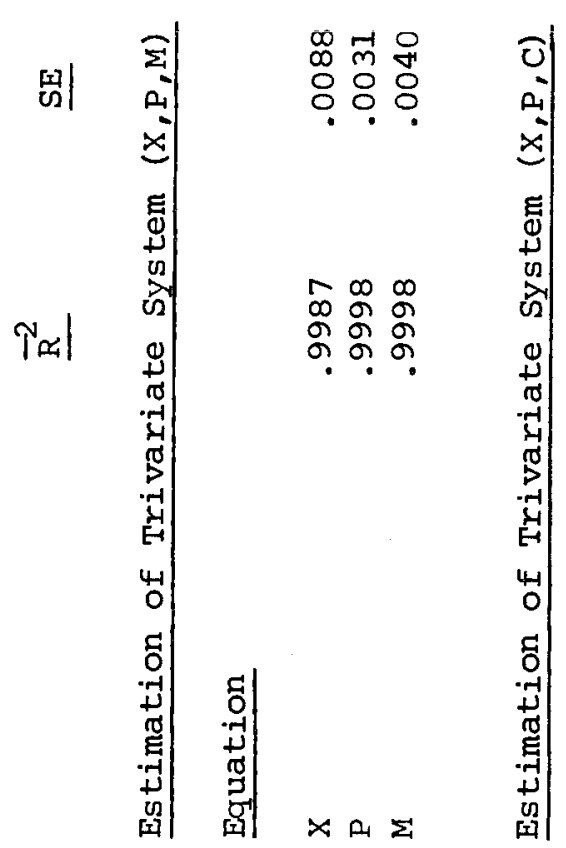

:

$\begin{array}{lll}9 & m & 1 \\ 9 & m & 0 \\ 0 & 0 & 0 \\ 0 & 0 & 0\end{array}$

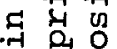

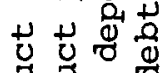

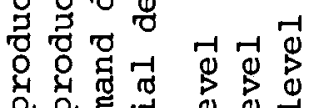

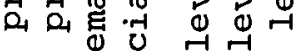

œ

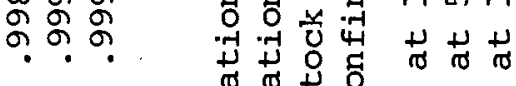

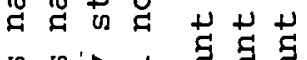

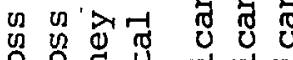

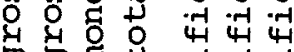

6 6 हा

II || || ||

$\rtimes n \sum U * \underset{*}{*}+\underset{*}{*}$

$\ddot{0}$
$\stackrel{u}{0}$
$\ddot{z}$ 
of the trivariate system consisting of real gross national product, the price deflator and the Ml money stock (hereafter called simply "money"). The lower half of the table presents analogous statistics for the estimation of the trivariate system consisting of real gross national product, the price deflator and total nonfinancial debt (hereafter called simply "credit"). Once again all variables are in natural logarithms, and each of the lag operator polynomials includes eight quarterly values. For each estimated equation the table shows the coefficient of multiple determination and the standard error, and, for each lag operator polynomial, the F-statistic for the test of the null hypothesis that the polynomial's coefficients are all equal to zero.

The results presented in Table 3 provide no basis whatever for distinguishing money from credit along lines that would warrant including the money market but excluding the credit market in macroeconomic models. The evidence indicates that neither money nor credit incrementally explains real income, given the explanatory power already contained in lagged values of real income and prices. By contrast, both money and credit do incrementally explain prices, this time given the explanatory power already contained in lagged values of prices (and of real income, which does not significantly contribute). Finally, both money and credit are incrementally explained by real income and by prices, even given the explanatory power of one another as well as of lagged values of money or credit, respectively.

Hence the evidence does not support the proposition that money holdings and nonfinancial behavior are jointly determined in some sense in which credit borrowings and nonfinancial behavior are not, nor does it support the proposition that money is prior to nonfinancial behavior while credit is not. Indeed, the results reject at the $1 \%$ level the proposition 
that money is predetermined with respect to either income or prices. By contrast, a test of the proposition that money is predetermined with respect to nominal income (that is, that nominal income does not incrementally explain money), as in Sims [18], would impose on the analysis the constraint that the respective coefficients of lagged real income and lagged prices must be identical in the equation explaining money - a constraint that the data decisively reject. ${ }^{15}$

Although the finding that real income and prices incrementally explain both money and credit is not surprising (at least not to this writer), the apparent absence of any effect of either money or credit on real income is somewhat surprising. Because prices apparently do incrementally explain real income (albeit weakly in the second system), while both money and credit incrementally explain prices, this result is not evidence for any straightforward classical neutrality proposition. Even so, it would be surprising if prices were a sufficient statistic for whatever information financial quantities conveyed about decisions with respect to real spending, output and income.

Table 4 helps to resolve this puzzle by presenting statistics, analor gous to those in Table 3, for the estimation of the four-variable vector autoregression system including both money and credit in addition to real gross national product and the price deflator. Apart from the expansion to include all four variables, the system summarized in Table 4 is identical to those represented by (5) above.

The contrast between the results for the four-variable system and the corresponding results for the two trivariate systems once again illustrates that whether or not one variable incrementally explains another depends crucially on the base from which the increment is measured - and not always 
횐

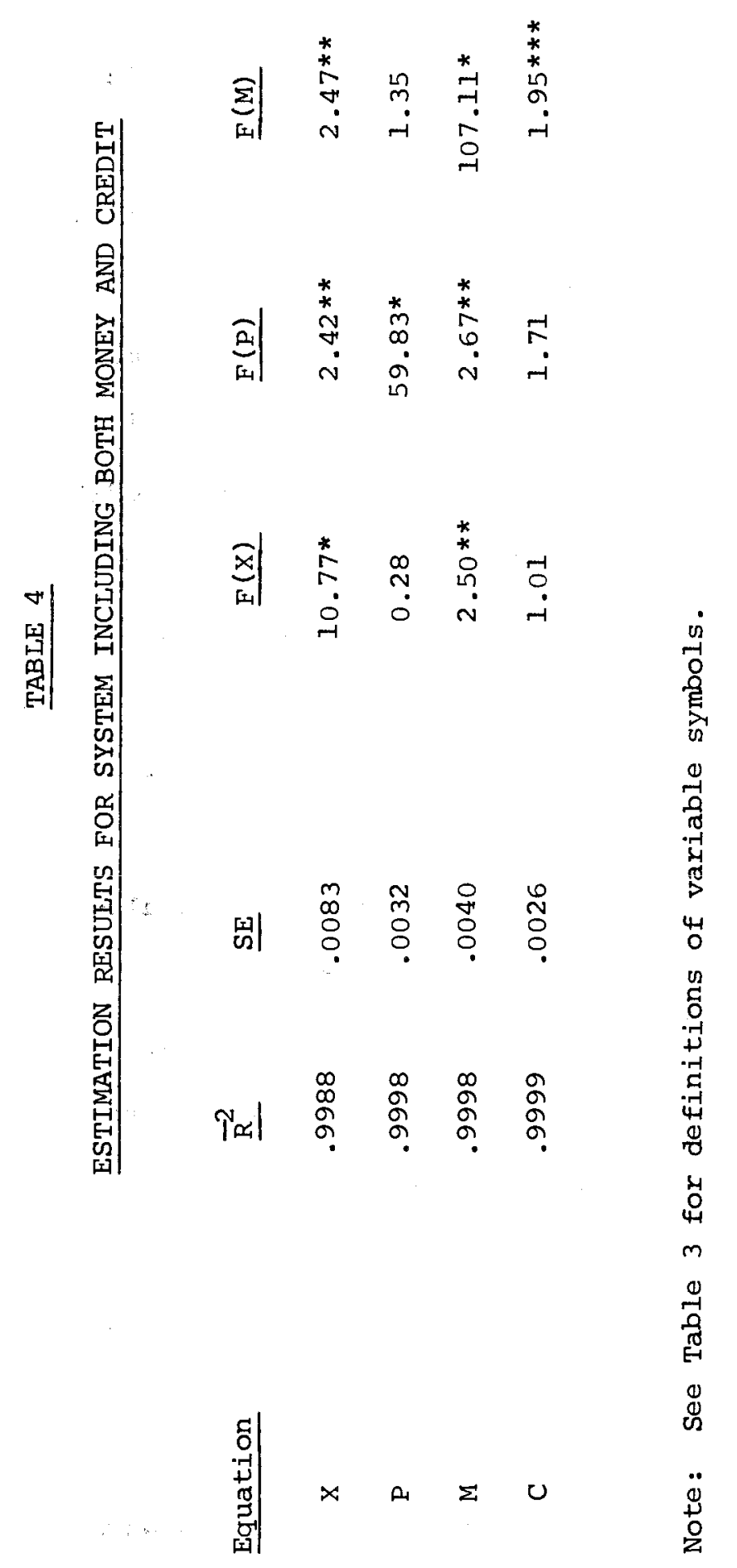


in the direction that a larger information base makes the relevant increment harder to detect. Although neither money nor credit incrementally explains real income in the absence of the other, both do so in the presence of one another. In intuitive terms, what appears to matter for the explanation of real income is neither money nor credit but, instead, the interrelation between the two. Moreover, even in the presence of both money and credit, prices still also incrementally explain real income. Hence the effect on income represented by the price variable is at least in part independent of the effect of financial quantities; prices are not a sufficient statistic for the relevant information contained in financial quantities, nor do money and credit even jointly constitute a sufficient statistic for the relevant information contained in prices.

The other results presented in Table 4 are less striking but interesting nonetheless. Although money and credit each incrementally explain prices in the absence of the other, neither does so in the presence of the other (and of lagged prices and real income). Hence money and credit both apparently convey largely the same information about the determination of prices, and neither contributes significantly beyond what is contained in the other. Credit does not incrementally explain money, nor does its presence overturn the result that both real income and prices do. By contrast, money does incrementally explain credit (although only weakly), and in the presence of money neither real income nor prices any longer do so.

The results of vector autoregression analysis of real income, prices, money and credit therefore do not provide any basis for focusing on money to the exclusion of credit in macroeconomic analysis. From the perspective of explaining the variation of real income, what appears to be important is neither money nor credit separately but the relationship between the two. From the 
perspective of explaining the variation of prices, either one will do, and the choice between them is largely arbitrary. ${ }^{16}$ Finally, the interrelationship between money and credit themselves is apparently not so simple as to warrant including one and not the other in the analysis. Macroeconomic analysis should be sufficiently broad to include both the money market and the credit market. 
III. The Market for Money and the Market for Credit

The conclusion that both the money market and the credit market should play an integral role in macroeconomic analysis immediately recalls Patinkin's [15] classic statement of the static neoclassical monetary equilibrium framework. In its full form this model includes four markets those for goods and services, labor, money and credit ${ }^{17}$ - but by invoking Walras' Law Patinkin was able to eliminate any one. He chose to eliminate the labor market and work with the markets for goods and services, money and credit. ${ }^{17}$

Figure 2 illustrates the sense in which the markets for money and credit are both fundamental in Patinkin's model. The object of the analysis here is to determine the price level $\mathrm{P}$ and interest rate $r$ - in other words, the two rates of exchange spanning the three markets. An equilibrium in $(r, P)$ space is determined by the joint intersection, as at point $E_{1}$, of the three curves representing the market-clearing $(r, P)$ combinations for the three markets: $\mathrm{Xx}$ for the goods and services market, MM for the money market and $\mathrm{CC}$ for the credit market. A change in the underlying conditions that shifts any of the three curves must also shift at least one of the others. For example, if the introduction of checkable money market mutual funds were to reduce people's demand for "money," and therefore shift the marketclearing curve for the money market from MM to $M M^{\prime}$ ', the logic of the budget constraints underlying the model's construction dictates that people would also either increase their demand for goods and services or decrease their demand for borrowing, or both. If only the demand for goods and services changed, the XX curve would shift so as to intersect both $M^{\prime} M^{\prime}$ and $C C$ at point E'. If only the demand for borrowing changed, CC would shift so as to intersect both $M^{\prime} M^{\prime}$ and $X X$ at E''. The figure as drawn shows a shift in both 


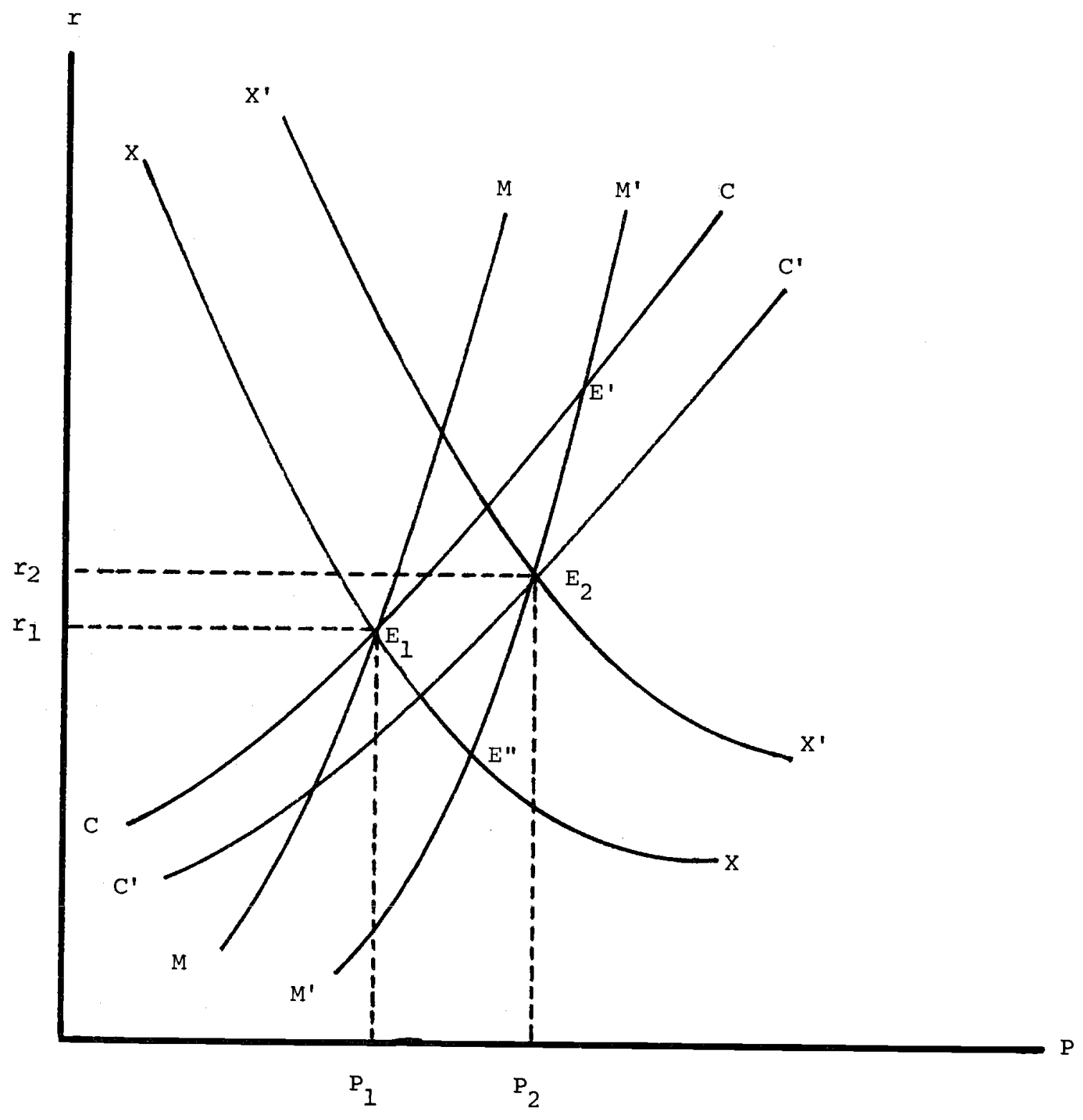

FIGURE 2

PATINKIN'S THREE-MARKET MODEL 
curves to a new equilibrium at $\mathrm{E}_{2}$.

Two lines are sufficient to determine a point, of course, so that even in this framework it still is formally possible to eliminate one of the three markets. What remains impossible, however, is to determine the effects of a change affecting any one market without, at the very least, making a potentially refutable assumption about a corresponding change in at least one other. In the example of the money market mutual fund, shifting $M M$ to $M^{\prime} M^{\prime}$ and leaving $X X$ in place, as is analogous to the practice in the more conventional Hicks-Keynes IS-LM analysis, is equivalent to assuming a specific shift in CC. Similarly, analyzing an increase in government spending that shifts $x X$ to $X^{\prime} X^{\prime}$ by leaving $M M$ in place is again equivalent to assuming a specific shift in CC. In either case, behavior in the credit market may or may not warrant such an assumption. The results presented in Tables 3 and 4 suggest that, at least from the perspective of the determination of real income (though not of prices, as in Patinkin's full employment model), it is not safe to assume that the credit market passively absorbs the necessary shifts in this way. Changes in the quantity of money may or may not have implications for real income, depending on what is happening to the quantity of credit.

In the context of this three-market representation of economic activity, the four-variable system summarized in Table 4 uses the quantity of credit to represent the relevant aspects of behavior in the credit market, while the remaining three variables represent the quantities in the other two markets (goods and services and money) and the rate of exchange between them. To the extent that the objective is simply to include some representation of the credit market, however, the quantity of credit is not the only logical choice for this purpose. The alternative is either the rate of 
exchange between credit and money in a market with nominal bonds, or the rate of exchange between credit and goods in a market with indexed bonds. Following Mehra's [13] demonstration that including the interest rate in the analysis is sufficient to reverse Sims' [18] earlier findings that money incrementally explains income but not vice versa, Sims [19] has estimated the analog to the system in Table 4 using the rate of exchange between credit and money - that is, the nominal interest rate - to represent the role of the credit market. Table 5 summarizes the results of estimating a fourvariable system like Sims', but using the same data and details of estimation as in the work presented above. ${ }^{19}$ The results are close to Sims', and they offer some interesting contrasts to those in Table 4 . The interest rate incrementally explains real income, while prices no longer do, nor does money. ${ }^{20}$ In the absence of the credit quantity, however, money once again incrementally explains prices. Real income again incrementally explains money, but in the presence of the interest rate prices no longer do. Money does not incrementally explain the interest rate here, although it does incrementally explain the credit quantity in Table 4.

Beyond the simple distinction between using the quantity variable and using the relative price variable to represent the third market, is there any relationship between the two systems summarized in Tables 4 and 5 ? Figure 3 shows two alternative representations of the credit market in a linear stochastic model. In each the intersection of the deterministic parts of the demand and supply curves $-D_{0}$ for borrowers and $S_{0}$ for lenders, respectively - indicates the expected equilibrium in $(r, c)$ space. In panel (a) only the demand curve is stochastic, and the resulting deviations of the interest rate and credit quantity around expected equilibrium $\left(r_{0}, c_{0}\right)$ are perfectly positively correlated. In panel (b) only the supply curve is 


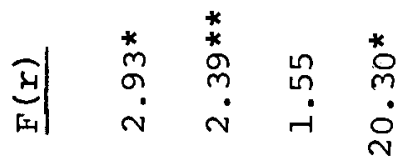

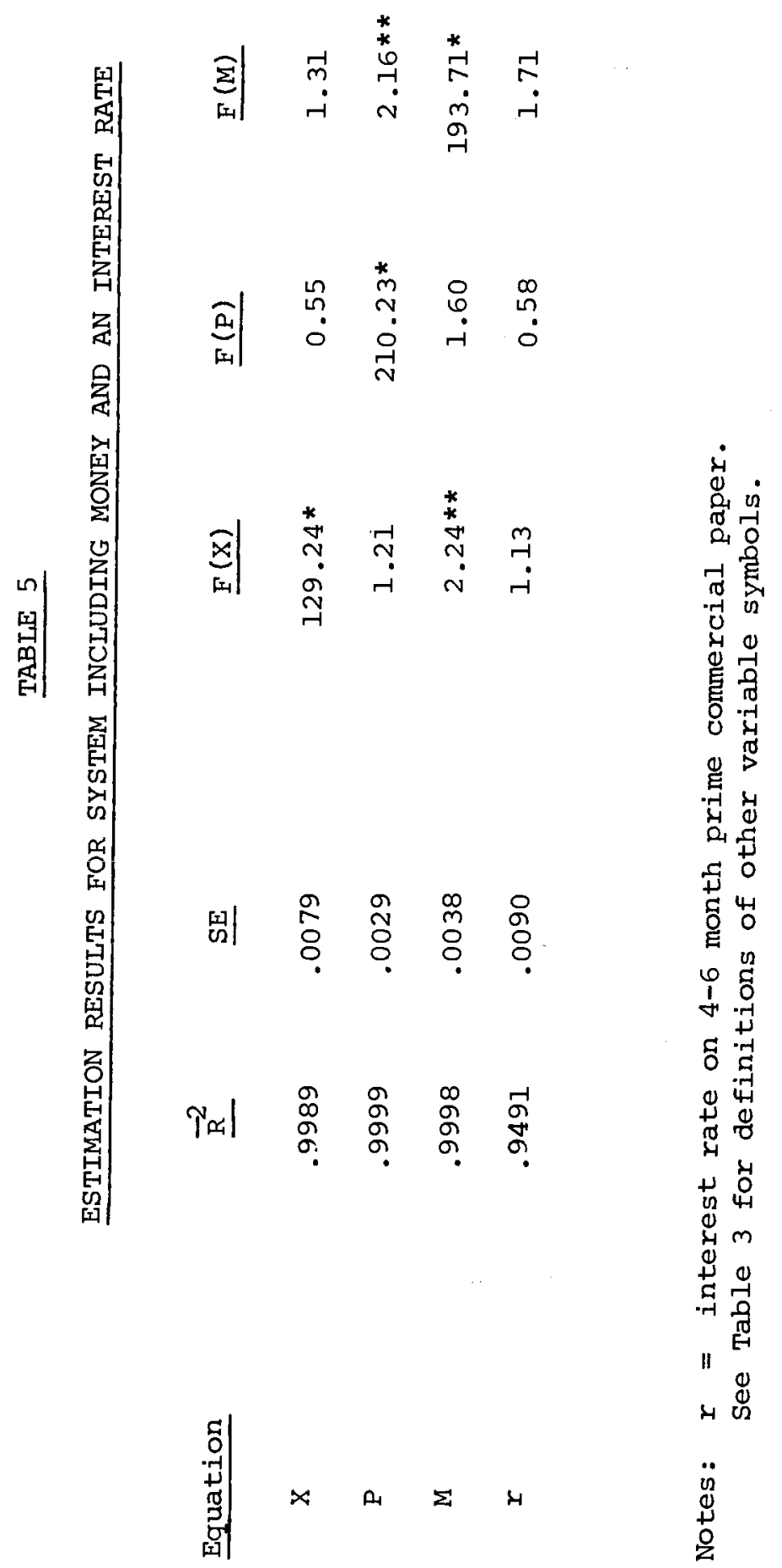




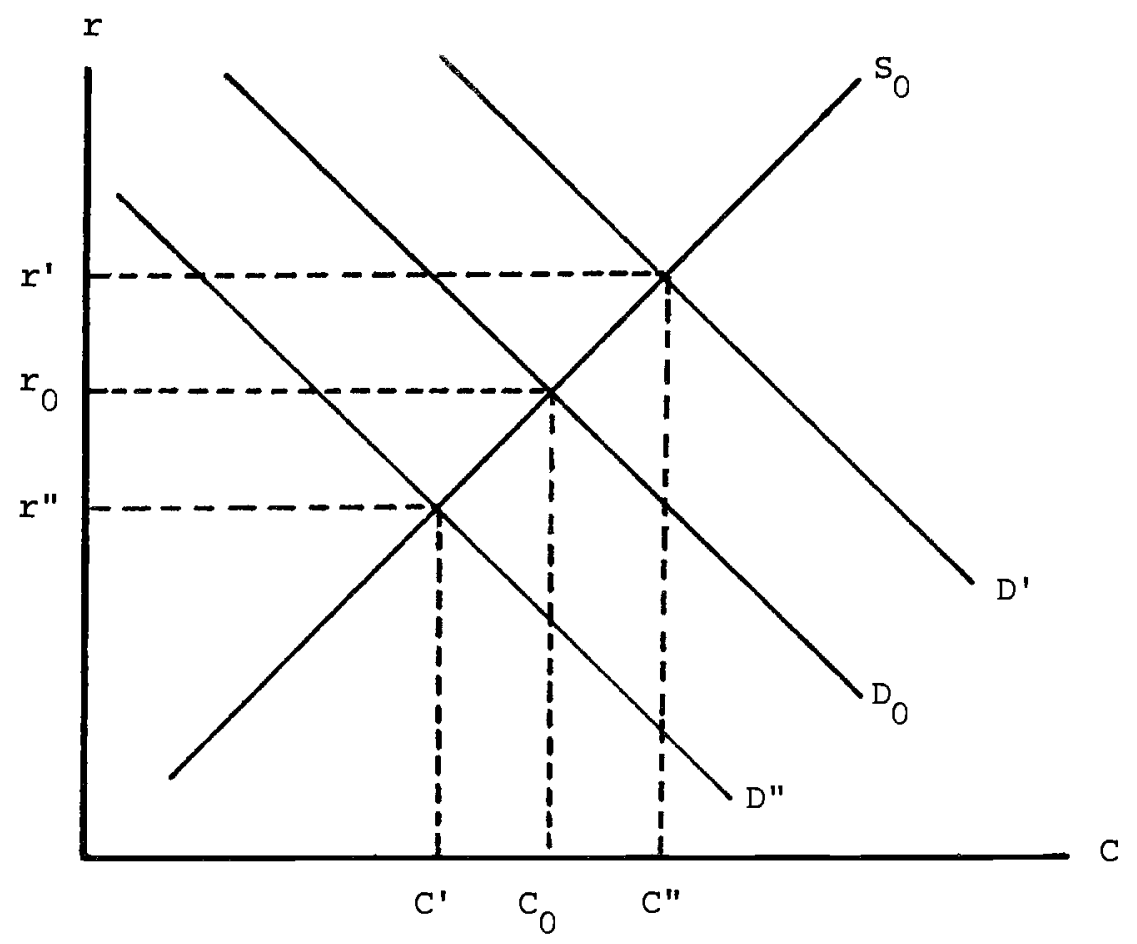

(a) Instability in Credit Demand

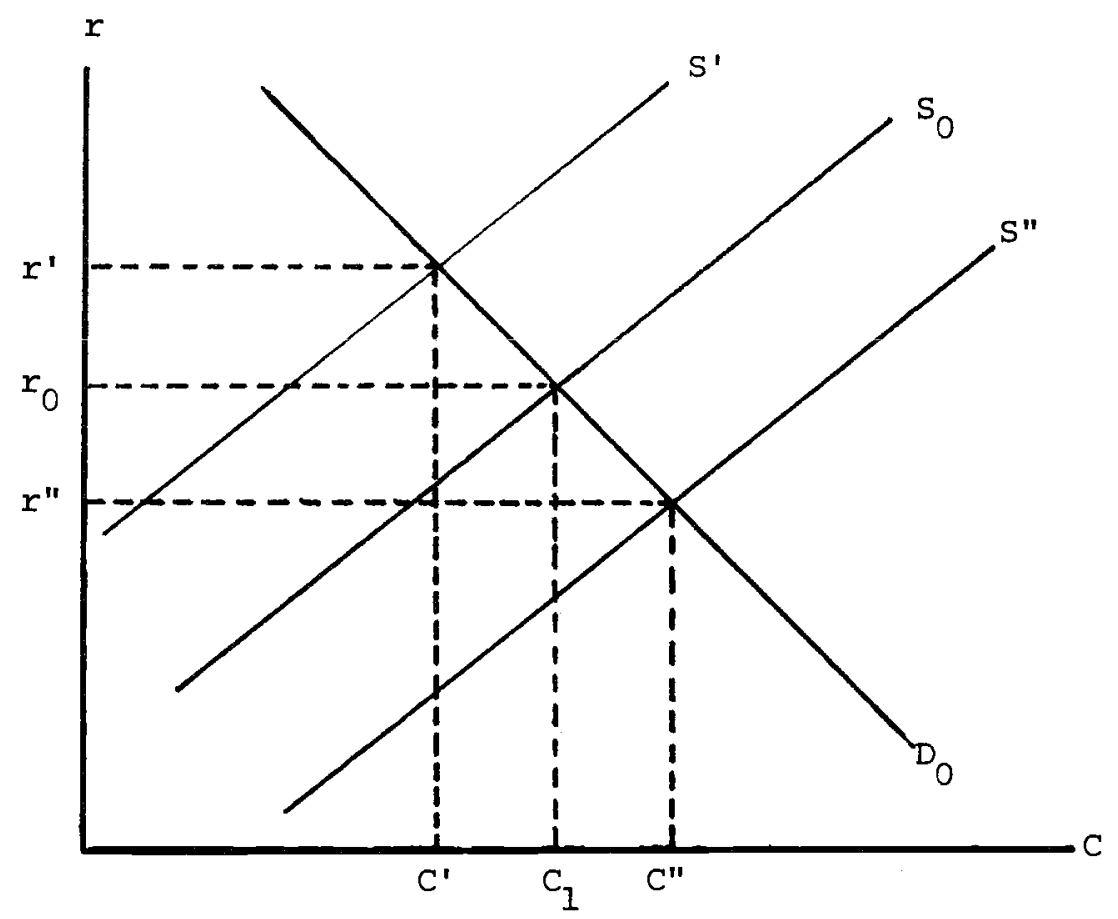

(b) Instability in Credit Supply

FIGURE 3 
stochastic, and the resulting deviations around $\left(r_{0}, C_{0}\right)$ are perfectly negatively correlated.

Both credit demand and credit supply are presumably stochastic in reality, so that the actual correlation will be imperfect. The value of the correlation coefficient constitutes potentially useful information, however. First, the correlation's sign will indicate whether the dominant source of stochastic variation in the credit market comes from the behavior of borrowers or lenders. Second, and more importantly, the correlation's absolute value will indicate to what extent a univariate representation of the credit market - either the interest rate or the credit quantity - is adequate. In the extreme case in which either credit demand or credit supply is nonstochastic, so that the correlation is perfect, either variable contains all of the relevant information about stochastic shifts in the credit market. At the other extreme, if credit demand and credit supply are both about equally stochastic (in independent ways), the two variables contain two separate sets of information, both of which are necessary.

Table 6 shows the pairwise correlations between the independent innovations associated with the credit quantity in the orthogonalized moving-average representation solved out from the four-variable vector autoregression system summarized in Table 4 and the independent innovations associated with the interest rate in the analogous representation of the system summarized in Table 5. Table 6 shows correlations between the innovations per se, as well as between their respective first differences. In addition, because the ordering assumed in the orthogonalization in general affects the computation of the innovations corresponding to particular variables, the table shows correlations for the innovations computed for credit and the interest rate ordered last in their respective systems (as in Table 2 above) and 


\section{CORRELATIONS BETWEEN CREDIT AND INTEREST RATE INNOVATIONS}

\section{Pairwise Correlations}

$$
\left(\varepsilon_{C^{\prime}} \varepsilon_{r}\right) \quad\left(\Delta \varepsilon_{C^{\prime}} \Delta \varepsilon_{r}\right)
$$

C,r ordered last

$.41 *$

$.50 *$

C, $r$ ordered first

.27 *

$.39 *$

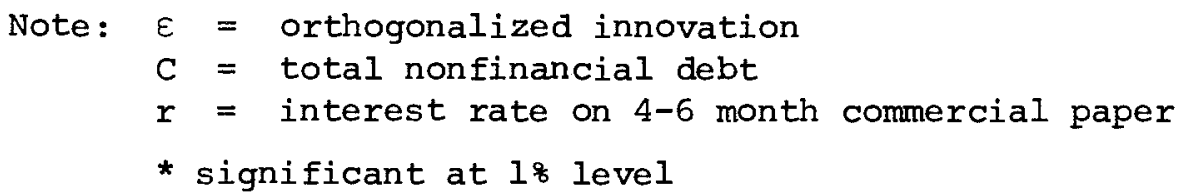


also for these variables ordered first. In each case the interest rate innovations are lagged one period so that the 4-6 month span of the interest rate approximately centers on the corresponding credit quantity observation (measured as of the end of the quarter).

The correlation between the two innovations is positive regardless of the details of the computation, indicating that credit demand - that is, the behavior of borrowers - is the dominant source of stochastic variation in the credit market. None of the correlations approaches unity, however, confirming that credit supply is also importantly subject to stochastic variation. Hence it is highly unlikely that either the credit quantity or the interest rate constitutes, by itself, a sufficient representation of the credit market.

Some representation of the credit market in macroeconomic analysis is clearly better than none, and the chief contribution of the four-variable systems presented in Tables 4 and 5 is that each includes one variable for this purpose: a quantity in the former and a relative price in the latter. Nevertheless, the evidence presented here suggests not only that macroeconomic analysis should explicitly incorporate the credit market but also that it should do so with both a quantity and a relative price variable. The resulting framework would then be a fully specified three-market model, including real income, money and credit (the quantities in all three markets) as well as the price level and the interest rate (the two rates of exchange spanning them). 20 
IV. Implications for Monetary Policy

The evidence presented in this paper supports three conclusions about the respective roles of money and credit in macroeconomic analysis:

First, the relationship between credit and nonfinancial economic activity is just as regular and stable as is that between money and economic activity. The evidence does not warrant including the money market but excluding the credit market on grounds of the closeness, or lack thereof, of the observed empirical relationships.

Second, real income and prices are not predetermined with respect to credit, any more so than they are with respect to money. The evidence does not warrant excluding either the credit market or the money market on grounds of being only peripheral to the determination of nonfinancial economic activity. Third, the interest rate and the quantity of credit both represent aspects of behavior in the credit market that matter for nonfinancial economic activity. The evidence suggests, however, that neither variable alone is adequate to convey all of the information about the credit market that is relevant to macroeconomic analysis.

These conclusions also bear parallel implications for the choice of framework for conducting monetary policy. The same evidence that rejects the propositions which, if true, would rationalize a special role for money over credit in analysis also rejects the corollary propositions which, if true, would rationalize a special role for money over credit in the design and execution of monetary policy. Hence this evidence suggests that there is little basis for the conventional monetary policy procedures currently in practice in the United States, as well as in most other industrialized Western economies, which revolve around specific target rates of growth for some measure (s) of the money stock with minimal attention paid to credit measures. 
One way to read the evidence developed in this paper is simply as further support for the case against having any kind of intermediate target for monetary policy at all. Under the intermediate target procedure, the central bank first determines for some financial quantity a time path believed to be consistent with achieving its ultimate objectives for the nonfinancial economy, and then acts as if its objective were to control that quantity so that its subsequent growth follows the chosen path to within a predetermined range of tolerance. Hence the intermediate target, which is observable on a timely basis in the financial markets, stands as a proxy for the ultimate nonfinancial objectives of monetary policy in a world characterized by uncertainty and lags of several kinds. In practice, central banks using the intermediate target procedure have typically chosen a measure of the money stock as the intermediate target, and the main impetus for the adoption of this procedure has usually rested at least in part on notions of the special relationship between money and nonfinancial economic activity.

In fact, the intermediate target procedure would constitute an optimal way to conduct monetary policy only under extremely stringent conditions describing the relationship between the intermediate target and the nonfinancial objectives of monetary policy. ${ }^{22}$ Even in the context of a simple macroeconomic model, for example, the intermediate target procedure based on the money stock as the intermediate target is optimal only if the demand for money is both perfectly stable and perfectly insensitive to interest rates.

In the wake of the widely publicized collapse of previously well accepted U.S. money demand functions during the 1970s, further evidence that the demand for money does not meet these conditions is hardly necessary. Even so, the evidence presented in this paper further strengthens the case 
against the intermediate target procedure by indicating the complexity of the relationship among money, credit and economic activity. Indeed, the evidence shows that there is no more empirical justification for using money as the intermediate target than there is for using credit as the intermediate target. To the extent that arguments for this way of conducting monetary policy have traditionally rested on the presumption that money plays a special role, and hence that money should serve as the intermediate target, this evidence casts further doubt on the appropriateness of the entire intermediate target procedure.

Even within the more limited context of the intermediate target procedure itself, the evidence presented in this paper suggests that at the very least a two-target framework based on one monetary aggregate target and one credit aggregate target would be superior to a framework based on monetary targets only, in the usual sense of delivering a greater likelihood of achieving outcomes for key nonfinancial variables falling within any given tolerance around corresponding set objectives. (The evidence even provides some ground for believing that a three-target policy, including an interest rate in addition to money and credit, would be superior still.)

How would monetary policy function in an explicit two-target moneyand-credit framework? Only with infinitesimal probability, of course, would the stated target for money and the stated target for credit ever turn out to be precisely compatible. The diversion between the two aggregates in an environment of uncertainty would indeed present a problem if the central bank were to interpret the intermediate target procedure in a strict sense. If, however, it instead regarded each intermediate target as an "information variable" which identified a limited set of incoming information to which there would be a presumption that the central bank would respond as a matter 
of course, there would be neither analytical nor practical difficulty in having two such targets instead of one. ${ }^{23}$ Indeed, according to the published policy records of the Federal Open Market Committee, as well as reports to the Congress by the Chairman of the Federal Reserve System, monetary policy in the United States currently uses just such a two-target framework, but with the Ml-B and M2 money stocks serving as the two targets.

The key advantage of an explicit two-target framework based on money and credit in comparison to a two-target framework based on two separate definitions of the money stock, however, would be the incorporation of a more diverse information base in the set of signals that presumptively matter for monetary policy. Money is, after all, an asset held by the public, and each monetary aggregate is just a different way of adding up the public's assets. The combination of an $\mathrm{M} 1-\mathrm{B}$ and an $\mathrm{M} 2$ target therefore relies solely on the asset side of the public's balance sheet, although it aggregates those assets in two separate ways. A framework based on a money target and a credit target.would instead establish a presumption that the central bank would respond to signals from both sides of the public's balance sheet, and the evidence presented here indicates that both sides of the balance sheet do contain information that is relevant to the determination of nonfinancial economic activity.

In sum, the evidence presented in this paper provides no support for the intermediate target procedure for monetary policy, as currently implemented with some measure(s) of the money stock used as the only intermediate target(s). The evidence is instead consistent with either abandoning the intermediate target procedure altogether and addressing monetary policy directly to its nonfinancial objectives, or else adopting a two-target monetary policy framework based on both money and credit. 


\section{Footnotes}

* I am grateful to Richard Clarida and Angelo Melino for research assistance; to them as well as Philip Cagan, John Lintner, Robert Litterman, Robert Shiller, Christopher Sims and Laurence Summers for helpful discussions and comments on an earlier draft; and to the National Science Foundation (grant DAR79-10519) and the Alfred P. Sloan Foundation for research support.

1. An exception in this regard is the role of the quantity of home mortgage lending in determining residential construction (and hence the level of income generally) in the MIT-Penn-SSRC model; see de Leeuw and Gramlich [ 4].

2. Indeed, one strand of literature seeks to define "money" simply as that asset aggregate which bears the closest empirical relationship to economic activity.

3. An exception is the work of Brunner and Meltzer, who have always emphasized the role of the monetary base; see, for example, [3].

4. I refer here to my own current research, which will be the basis of a forthcoming paper encompassing all four of these countries, as well as to work by Islam [1I] on Germany and Japan.

5. The concept of these analyses' being prior to structural model building is in the sense of zellner and Palm [22] and sargent [16]. It is not to be confused with the proposition that such analyses are a substitute for structural model building.

6. This section draws heavily on my earlier papers $[6,7]$; see especially [6] for the full set of results.

7. In part because of the capital export controls that were in effect during 1964-74, foreign obligors have accounted for only a small fraction of borrowing in U.S. markets throughout this period. Including foreign borrowers would make little difference to the analysis that follows.

8. With the exception of the depression years and (less so) World War II, the stability in fact goes back at least to 1921 when the ratio stood at $141.9 \%$; see again [6].

9. Apart from the equation for $M 3$, which is based on a shorter sample period because of limited data availability, the F-statistic for a break at 1970 is significant at the $10 \%$ level for all of these equations and at the $5 \%$ level for all but two (total debt and total net assets).

10. Among the most important criticisms of the St. Louis approach have been those of Goldfeld and Blinder [8], Sargent [17], and Modigliani and Ando [14]. The methodology underlying the tests described below is due largely to Granger and Sims; see especially Sims [18]. 
11. The orthogonalization procedure is

$$
\begin{aligned}
\left|\begin{array}{ll}
\phi_{11} & \phi_{12} \\
\phi_{21} & \phi_{22}
\end{array}\right| & =\left|\begin{array}{ll}
\theta_{11} & \Theta_{12} \\
\theta_{21} & \Theta_{22}
\end{array}\right|\left|\begin{array}{ll}
1 & 0 \\
\lambda & 1
\end{array}\right| \\
\left|\begin{array}{ll}
\varepsilon_{1 t} \\
\varepsilon_{2 t}
\end{array}\right| & =\left|\begin{array}{cc}
1 & 0 \\
-\lambda & 1
\end{array}\right|\left|\begin{array}{l}
\mu_{1 t} \\
\mu_{2 t}
\end{array}\right|
\end{aligned}
$$

for $\lambda=\operatorname{cov}\left(\mu_{1}, \mu_{2}\right) / \operatorname{var}\left(\mu_{1}\right)$. This orthogonalization is equivalent to placing $F$ last in the pairwise causal ordering of $Y$ and $F$. The alternative ordering placing $F$ first, which follows from transposing the $\lambda($ or $-\lambda$ ) and the zero elements, gives results that are close to those reported below; see [6].

12. Analogous simulations for the M3 money stock, net financial assets and non-federal debt all support this contrast. Bank credit also appears to be stable, however.

13. See, for example, Tobin [20] and Zellner [21].

14. The contrast between the results of sims [18] and the results of Mehra [13] and Sims [19], discussed below, is a striking example of this phenomenon.

15. The F-statistic for this additional constraint is 2.22 , which is significant at the 5\% level. Moreover, results for the bivariate system which does impose this constraint also reject at the $1 \%$ level (F-statistic 2.89) the proposition that nominal income does not incrementally explain money.

16. Only at the $1 \%$ significance level is it true that money incrementally explains prices while credit does not.

17. Patinkin referred to all debt instruments as "bonds" and, for simplicity, assumed that they were perpetuities. In reality the instruments included in the total nonfinancial debt aggregate span the entire maturity spectrum but, at least for the United states, do not include perpetuities. What actually matters for the pricing of debt instruments is not stated maturity anyway but the duration (see, for example, Hopewell and Kaufman [10]) which is always shorter for coupon-bearing instruments, especially after allowance for the probability of call (see Bodie and Friedman [ 2 ]).

18. The choice of the labor market was perhaps appropriate for Patinkin's equilibrium analysis, but, as subsequent work (Barro and Grossman [1], for example) has shown, the labor market is apparently central to disequilibrium analysis.

19. Sims used monthly data, industrial production instead of real gross national product, and the wholesale price index instead of the gross national product deflator. 
20. The finding that the nominal interest rate renders the price variable insignificant everywhere except in the price equation is not surprising since, with an eight-quarter lag, the F-test for prices is hard to distinguish from an $F$-test for the inflation rate.

21. A forthcoming paper will report my analysis of such a five-variable system.

22. See Friedman [5].

23. See Kareken et al. [12] and Friedman [5] for the development of the "information variable" concept in the context of intermediate targets for monetary policy. 


\section{$\underline{\text { References }}$}

1. Barro, Robert J., and Grossman, Herschel S. "A General Disequilibrium Model of Income and Employment." American Economic Review, LXI (March, 1971), 82-93.

2. Bodie, Zvi, and Friedman, Benjamin M. "Interest Rate Uncertainty and the Value of Bond Call Protection." Journal of Political Economy, LXXXVI (February, 1978), 19-43.

3. Brunner, Karl, and Meltzer, Allan H. "Money, Debt and Economic Activity." Journal of Political Economy, Lxxx (September/October, 1972), 951-977.

4. DeLeeuw, Frank, and Gramlich, Edward. "The Channels of Monetary Policy: A Further Report on the Federal Reserve - M.I.T. Model." Journal of Finance, XXIV (May, 1969), 265-290.

5. Friedman, Benjamin M. "Targets, Instruments and Indicators of Monetary Policy." Journal of Monetary Economics, I (October, 1975), 443-473.

6. Friedman, Benjamin M. "The Relative Stability of Money and Credit 'Velocities' in the United States: Evidence and Some Speculations." Mimeo, National Bureau of Economic Research, 1981.

7. Friedman, Benjamin M. "Debt and Economic Activity in the United states. Friedman (ed.), The Changing Roles of Debt and Equity in Financing U.S. Capital Formation. Chicago: University of Chicago Press, forthcoming.

8. Goldfeld, stephen M., and Blinder, Alan S. "Some Implications of Endogenous Stabilization Policy." Brookings Papers on Economic Activity (No. 3, 1972),

9. Granger, C.W.J. "Investigating Causal Relations by Econometric Models and Cross-Spectral Methods." Econometrica, XXXVII (July, 1969), 424-438.

10. Hopewell, Michael H., and Kaufman, George G. "Bond Price Volatility and Term to Maturity: A Generalized Respecification." American Economic Review, LXXII (September, 1973), 749-753.

11. Islam, Shafiqul. "Monetary and Credit Aggregates as Intermediate Targets: Empirical Evidence from Three Industrial Countries." Mimeo: Federal Reserve Bank of New York, 1981.

12. Kareken, J.H., Muench, T., and Wallace, N. "Optimal Open Market Strategy: The Use of Information Variables." The American Economic Review, LXIII (March 1973), 156-172.

13. Mehra, Y.P. "Is Money Exogenous in Money-Demand Equations." Journal of Political Economy, LXXXVI (April, 1978), 211-228. 
14. Modigliani, Franco, and Ando, Albert. "Impacts of Fiscal Actions on Aggregate Income and the Monetarist Controversy: Theory and Evidence." Stein (ed.), Monetarism. Amsterdam: North-Holland Publishing Company, 1976.

15. Patinkin, Don. Money, Interest and Prices. 2nd ed. New York: Harper \& Row, 1965.

16. Sargent, Thomas J. "A Classical Macroeconomic Model of the United States." Journal of Political Economy, LXXXIV (April, 1976), 207-237.

17. Sargent, Thomas J. "The Observational Equivalence of Natural and Unnatural Rate Theories of Macroeconomics." Journal of Political Economy, LXXXIV (June, 1976), 631-640.

18. Sims, Christopher A. "Money, Income and Causality." American Economic Review, LXII (September, 1972), 540-552.

19. Sims, Christopher A. "Comparison of Interwar and Postwar Business Cycles: Monetarism Reconsidered." American Economic Review, LXX (May, 1980), 250-257.

20. Tobin, James. "Money and Income: Post Hoc Ergo Propter Hoc." guarterly Journal of Economics, LXXXIV (May, 1970), 301-317.

21. Zellner, Arnold. "Causality and Econometrics." Brunner and Meltzer (eds.), Three Aspects of Policy and Policymaking: Knowledge, Data and Institutions. Amsterdam: North-Holland Publishing Company, 1979.

22. Zellner, Arnold, and Palm, Franz. "Time Series Analysis and Simultaneous Equation Econometric Models." Journal of Econometrics, II (May, 1974), 17-54. 